\title{
Genetic and morphological studies of Trichosirocalus species introduced to North America, Australia and New Zealand for the biological control of thistles
}

\author{
A. De Biase ${ }^{1 *}$, E. Colonnelli $^{2}$, S. Belvedere ${ }^{1}$, A. La Marca ${ }^{3}$, \\ M. Cristofaro ${ }^{4}$ and L. Smith ${ }^{5}$ \\ ${ }^{1}$ Dipartimento di Biologia e Biotecnologie 'Charles Darwin', Università di \\ Roma La Sapienza, Viale dell'Università 32, 00185 Rome, Italy: ${ }^{2}$ Via delle \\ Giunchiglie 56, 00172 Rome, Italy: ${ }^{3}$ BBCA-onlus, Via Angelo Signorelli 105, \\ 00123 Rome, Italy: ${ }^{4}$ ENEA C.R. Casaccia SSPT-BIOAG-PROBIO, Via \\ Anguillarese 301, 00123 S. Maria di Galeria (Rome), Italy: ${ }^{5}$ USDA-ARS, 810 \\ Avenue du Campus Agropolis, 34980 Montferrier-sur-Lez, France
}

\begin{abstract}
Trichosirocalus horridus sensu lato has been used as a biological control agent of several invasive thistles (Carduus spp., Cirsium spp. and Onopordum spp.) since 1974. It has been recognized as a single species until 2002, when it was split into three species based on morphological characters: T. horridus, Trichosirocalus briesei and Trichosirocalus mortadelo, each purported to have different host plants. Because of this taxonomic change, uncertainty exists as to which species were released in various countries; furthermore, there appears to be some exceptions to the purported host plants of some of these species. To resolve these questions, we conducted an integrative taxonomic study of the T. horridus species complex using molecular genetic and morphological analyses of specimens from three continents. Both mitochondrial cytochrome c oxidase subunit I and nuclear elongation factor $1 \alpha$ markers clearly indicate that there are only two distinct species, T. horridus and T. briesei. Molecular evidence, morphological analysis and host plant associations support the synonymy of T. horridus (Panzer, 1801) and T. mortadelo Alonso-Zarazaga \& Sánchez-Ruiz, 2002. We determine that T. horridus has been established in Canada, USA, New Zealand and Australia and that T. briesei is established in Australia. The former species was collected from Carduus, Cirsium and Onopordum spp. in the field, whereas the latter appears to be specific to Onopordum.
\end{abstract}

Keywords: biological control, molecular taxonomy, synonymy, thistles, Trichosirocalus horridus species complex, weevils

(Accepted 9 October 2015)

\section{Introduction}

*Author for correspondence

A. De Biase

Phone: +390649914744

Fax: +39064958259

E-mail: alessio.debiase@uniroma1.it
The genus Trichosirocalus Colonnelli, 1979 (Coleoptera, Curculionidae, Ceutorhynchinae) includes 17 Palaearctic species (Colonnelli, 2013), mainly feeding on Plantaginaceae and Asteraceae (Colonnelli, 2004). Weevils originating from Italy and Germany, identified at the time as Trichosirocalus horridus (Panzer, 1801), were released in Canada, USA, New Zealand 


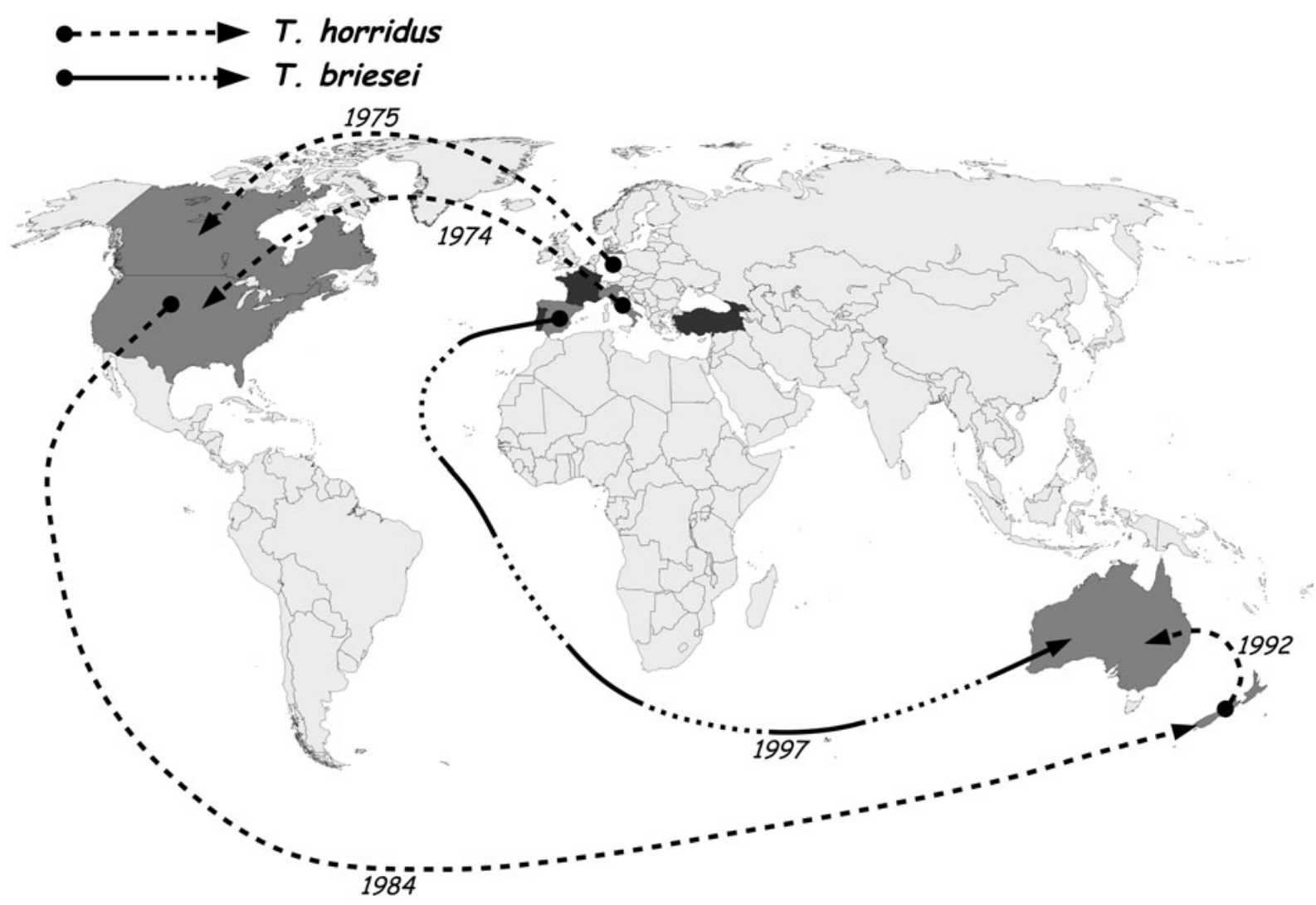

Fig. 1. Map showing the introductions of Trichosirocalus horridus sensu lato to Canada, USA, New Zealand and Australia. Medium grey countries were involved in translocation events as described in the text. Dark grey countries were included in the sampling to get more data on biological variation of the species complex. Both light and dark grey countries were sampled for the present study. Base Map from http://commons.wikimedia.org/wiki.

and Australia for classical biological control of Musk thistle (Carduus nutans L.) and its close relatives (Kok \& Trumble, 1979; Harris, 1984; Jessep, 1989; Woodburn, 1997). In 1997, weevils associated with Scotch thistle (Onopordum acanthium L.) in Spain were introduced to Australia (Briese et al., 2002a; Briese, 2012). Until 2002, T. horridus (Panzer, 1801) was considered as single species, known to be associated in the larval and/or adult stages with several species of thistles of the tribe Cardueae (Carduus spp., Cirsium spp., Onopordum spp, Silybum marianum (L.) Gaertn and Galactites tomentosa Moench) (Zwölfer, 1965). Alonso-Zarazaga \& Sánchez-Ruiz (2002), from a morphological study of samples collected by D. Briese in Australia on Carduus (T. horridus was released in Australia in 1985 as control agent against Carduus thistles), as well as samples from the Australian quarantine stock originally collected on Onopordum in Spain, concluded that T. horridus was a complex of three species, which differed in host range and geographical distribution. Accordingly, T. horridus sensu stricto, feeds on Cirsium spp. and occurs in Spain, France, Germany and Croatia, Trichosirocalus mortadelo AlonsoZarazaga \& Sánchez-Ruiz (2002), feeds on Carduus spp. and is known from Australia and Germany (Hannover) and Trichosirocalus briesei Alonso-Zarazaga \& Sánchez-Ruiz (2002), feeds on Onopordum spp. and occurs in Austria, Morocco and Spain. Thus, the T. horridus complex was believed to encompass three very closely related species primarily distributed in South and Central Europe; however, it was not clear which species were introduced to North America, Australia and New Zealand.

Members of this species complex have been repeatedly translocated in biocontrol programmes against several thistles (fig. 1). First, colonies of T. horridus originating from Carduus in Italy were established to control Carduus thistles in the USA (Virginia, Kansas, Nebraska and Montana) in 1974 (Kok, 1978, 2001; Kok \& Trumble, 1979). Weevils collected from Germany (Neuenburg) were introduced to Canada in 1975 to control Carduus spp. (Harris, 1984; De Clerck-Floate \& Cárcamo, 2011). In 1984, specimens of T. horridus from the Canadian colony were introduced to New Zealand (Jessep, 1989), and in 1992 individuals from populations established in New Zealand were released in Australia to control Carduus spp. In the 1990s, Briese and colleagues carried out a field survey in Europe to seek prospective control agents to manage Onopordum thistles in Australia (Briese et al., 1994, 2002a). They discovered in Spain a population of the T. horridus complex apparently restricted to develop on Onopordum thistles, as suggested by the host range tests performed in an Australian quarantine laboratory (Briese et al., 2002b, c). These weevils were described as a new species ( $T$. briesei) by Alonso-Zarazaga \& Sánchez-Ruiz (2002) and released in Australia for the control of O. acanthium (Woodburn, 1997). Although the identity of insects in the latter introduction 
was clear, it was uncertain whether T. horridus and/or T. mortadelo had previously been introduced in each of the above countries.

In North America, T. horridus has been reared from both Carduus and Cirsium species (McAvoy et al., 1987; Takahashi et al., 2009; Wiggins et al., 2009), which suggests either the presence of two species of weevil ( $T$. horridus on Cirsium and T. mortadelo on Carduus) or that at least one of the species is not as specific as Alonso-Zarazaga \& Sánchez-Ruiz (2002) claimed. Furthermore, the weevils have been found on Cirsium, Carduus and Onopordum in New Zealand despite the introduction of only one population from Canada (Groenteman et al., 2008). Because of concern about risk to non-target plant species and the need to better understand the specificity of biological control agents of weeds, it is important to clarify the taxonomic status of these species and their host specificity. Molecular genetic analysis has often contributed to the discovery of cryptic species that differ in important biological traits, including host specificity (Fumanal et al., 2005; Madeira et al., 2006; Mound et al., 2010; Gaskin et al., 2011). Furthermore, combining morphological, genetic and biological traits, known as integrative taxonomy, can provide a more robust and stable classification (Dayrat, 2005; Padial et al., 2010).

The goal of this paper is to reassess the taxonomy of the species in the T. horridus complex using a combination of molecular genetic, morphological and host plant data.

\section{Materials and methods}

\section{Sampling of investigated populations}

Samples of adult weevils were collected during field trips carried out in Spain, Portugal, France, Italy, Turkey and Georgia between 2008 and 2013 to obtain specimens from several distinct localities. In addition, many adult specimens were kindly provided by several colleagues from Germany, the USA, Canada, Australia and New Zealand, and a few larvae from New Zealand were provided by R. Groenteman (Landcare Research, Lincoln, New Zealand). These larvae were of particular interest because they had been collected from all the currently recorded host plants (Carduus, Cirsium, Onopordum) of the T. horridus complex. A few specimens of Trichosirocalus troglodytes (Fabricius, 1787), used as an outgroup taxon in the statistical analyses, were collected during a field trip in Portugal in 2013 by one of us (Enzo Colonnelli). Figure 1 displays the countries in which the studied samples were collected, and Table S1 (see supplementary material) lists the details of the localities and host plants. To record the trophic range of the taxonomic entities under study, during the fieldwork, the host plant of each collected adult specimen was identified by the field collectors. Insect voucher specimens are preserved in the authors' collections.

\section{Molecular genetic analysis}

Following the procedure described in Cristofaro et al. (2013), the total genomic DNA was extracted and used as a template in polymerase chain reactions (PCR; Mullis et al., 1986) to amplify a fragment of the mitochondrial genome coding for the cytochrome c oxidase subunit I (cox1) and a fragment of the nuclear gene coding for the elongation factor $1 \alpha$ (ef1 $\alpha$ ). Folmer's primers LC01490 and HC02198 (Folmer et al., 1994) were used to amplify the $5^{\prime}$ upstream region of the cox1 gene, or, when needed, the TY-J-1460 primer of Simon et al. (1994) as the forward one; few individuals not giving clean PCR results were amplified as described by Rector et al. (2010). The primers EF1-Bf and EF1-Br (HernandezVera et al., 2010), forward and reverse, respectively, were used to amplify the ef $1 \alpha$ gene. We used several PCR thermal cyclers among those available at our laboratory (i.e., Perkin Elmer ${ }^{\circledR}$ GeneAmp PCR System 2400 thermal cycler; MWG $^{\circledR}$ Biotech Primus 25, Biometra ${ }^{\circledR}$ Tpersonal 48), with the following amplification conditions: (a) $\operatorname{cox} 1$ : $94^{\circ} \mathrm{C}$ denaturation (5 min), followed by 35 cycles of $95^{\circ} \mathrm{C}$ denaturation $(1 \mathrm{~min})$, $40^{\circ} \mathrm{C}$ annealing $(1 \mathrm{~min})$, and $72^{\circ} \mathrm{C}$ extension ( $1 \mathrm{~min}$ and $30 \mathrm{~s}$ ), followed by a final 7 min elongation step at $72^{\circ} \mathrm{C}$; (b) efl $\alpha$ : touchdown PCR with $94^{\circ} \mathrm{C}$ denaturation $(2 \mathrm{~min}$ ), followed by 24 cycles of $94^{\circ} \mathrm{C}$ denaturation $(30 \mathrm{~s}), 62-50^{\circ} \mathrm{C}$ annealing (1 min; decreasing $2^{\circ} \mathrm{C}$ every 2 cycles), and $72^{\circ} \mathrm{C}$ extension ( $1 \mathrm{~min}$ ), followed by 2 cycles of $94^{\circ} \mathrm{C}$ denaturation $(30 \mathrm{~s}), 48^{\circ} \mathrm{C}$ annealing $(1 \mathrm{~min})$, and $72^{\circ} \mathrm{C}$ extension $(1 \mathrm{~min})$, followed by a final $7 \mathrm{~min}$ elongation step at $72^{\circ} \mathrm{C}$. Reactions were performed in $25 \mu \mathrm{l}$ of cocktail containing $\left(\mathrm{NH}_{4}\right)_{2} \mathrm{SO}_{4} 16 \mathrm{mM}$, Tris- $\mathrm{HCl} 67 \mathrm{mM}$ ( $\mathrm{pH} 8.8$ at $25^{\circ} \mathrm{C}$ ), $\mathrm{MgCl}_{2} 3 \mathrm{mM}$, Tween-20 $0.01 \%, 1 \mathrm{mM}$ of each deoxynucleotide, $0.8 \mathrm{pM}$ of each primer, and 1.25 units of Taq DNA polymerase (Bioline Reagents Ltd, UK). Amplified products were purified by Exo-SAP enzymatic reactions and sequenced at the Macrogen Korea (Seoul, Korea) and Macrogen Europe (Amsterdam, The Netherlands) genomic centres, employing Applied Biosystems ${ }^{\circledR}$ 3730xl DNA Analysers and using the BigDye Terminator Kit (Applied Biosystems, USA) according to the manufacturer's protocol. Sequencing primers were LC01490 and EF1-Bf for the mitochondrial and nuclear markers, respectively. When needed, the DNA of a few individuals was sequenced on both strands using the same reverse primers used during the PCR amplifications.

The acquired sequences were screened by a blast search of the GenBank nucleotide collection of the National Center for Biotechnology Information (NCBI) using the Mega BLAST procedure (Wheeler et al., 2007) available at its website (http://www.ncbi.nlm.nih.gov/blast). The screening procedure was aimed at checking the assignment of the specimens to high-level categories (e.g., family and subfamily). Next, the sequences were edited and aligned using the Staden Package ver. 2006.1.7.0 software (Staden et al., 1999). All peaks were checked for wrong base calls and noise and were cleaned when required. The two alignments were visually assessed without requiring any insertion-deletion (indel) typing for the $\operatorname{cox} 1$ gene, whereas for the nuclear ef $1 \alpha$ gene a little indel typing was needed within the encompassed intronic region. The latter sequences were also checked for heterozygous positions, and the gametic phases, where needed, were inferred with PHASE version 2.1 (Stephens et al., 2001). Finally, both alignments were collapsed using FaBox tool (Villesen, 2007) to retain the scored haplotypes only.

\section{Statistical analyses}

Divergence analyses and Neighbour-Joining (NJ; Saitou \& Nei, 1987) tree inference were performed for both markers by means of Molecular Evolutionary Genetics Analysis, version 5.2 (MEGA5), setting the $p$ uncorrected model for the genetic distance values computation (Tamura et al., 2007). Confidence at tree nodes was determined by bootstrapping 1000 times over the data. Genetic divergence was estimated as $p$ 
uncorrected distance computed as net averages among the groups scored on the inferred NJ topology.

Bayesian analyses were performed using Beast version 1.8.0 (Drummond et al., 2012) under the substitution model (s) selected by AICc in jModelTest 2 for each marker/partition analysed (Darriba et al., 2012). The HKY + I + G substitution model was selected for cox 1 , while the ef1 $\alpha$ nuclear marker was modelled by setting three partitions, namely the coding and noncoding regions of the gene (exons and introns both with HKY substitution model with estimated base frequencies and no model for site heterogeneity) and the indels that were scored during the alignments of the sequences (stochastic Dollo model). We used the lognormal relaxed-clock model implemented in the software to take into account the variation of the substitution rate among lineages (prior distribution set as Exponential with initial value 1.0, mean 10.0 and offset 0.0 ). The tree prior was set using the Constant coalescent Kingman model (Kingman, 1982). The analysis was carried out using a random starting tree, running two Markov chains for $50 \times 10^{6}$ generations and sampling every 1000 generations. Finally the same analysis was performed sampling from priors only to evaluate the priors that we applied to the various parameters. Convergence was evaluated with Tracer version 1.6 (Rambaut et al., 2013), and the two chains were combined with Logcombiner routine of Beast, discarding 12,500 burn-in trees each; the combined set of trees for each marker was summarized as a Maximum clade credibility tree with Beast's Treeannotator routine.

Degree of genetic divergence is related to the taxon under study, and there is no universal yardstick for unequivocally assigning a taxonomic rank to a scored value of genetic divergence (Blaxter, 2004; Moritz \& Cicero, 2004). This is a key problem when studying species, or populations, closely related to each other or recently diverged. The issue is commonly referred to as the species delimitation problem. Authors adopting the barcoding approach argue that a certain amount of genetic divergence between groups, contrasted to the within-groups divergence (barcoding gap) should be used as a guideline for species delimitation (Hebert et al., 2004). This approach has been enthusiastically supported or criticized owing to many issues related to sampling effort, incomplete lineage sorting and hybridization of recently diverged species and so on (Tautz et al., 2003; Janzen, 2004; Moritz \& Cicero, 2004; De Salle et al., 2005; DeSalle, 2006). Recent years have seen many discussions and contributions on this issue, producing several noteworthy methods (Wiens, 2007; Ence \& Carstens, 2011; Fujita et al., 2012). We have adopted three models/methods to analyse our datasets: (a) a classical phylogenetic approach by using both the NJ algorithm and the Bayesian inference implemented in Beast (Drummond et al., 2012); (b) the Automatic Barcoding Gap Discovery (ABGD) approach (Puillandre et al., 2012), as a fast and simple method to discover partitions in our datasets; and (c) the General Mixed Yule Coalescent (GMYC) model (Pons et al., 2006; Fontaneto et al., 2007; Monaghan et al., 2009; Fujisawa \& Barraclough, 2013), which helps in seeking the threshold that marks the transition between evolutionary dynamics within and among species, thus suggesting those clusters to be considered as distinct species on a phylogenetic tree.

The ABGD method (Puillandre et al., 2012) stems from the barcoding methodology, which was originally focused on the identification of biological samples using a standard nucleotide sequence (a $5^{\prime}$ fragment of the mitochondrial cox 1 gene) compared with a reference dataset of previously characterized species. The method aims at defining partitions in a set of cox 1 sequences that must be considered as hypotheses of prospective distinct species to further investigate in an integrative framework. The partitions are defined by analysing the distribution of all pairwise distances between sequences in order to locate the most reliable 'barcode gap' between the intraspecific and interspecific divergence. After the initial partitions are defined, the algorithm is performed in a recursive way until no new partitions are defined. Our analyses were carried out on the alignment of all 165 cox 1 sequences of the analysed ingroup (T. horridus species complex) by using the ABGD method as available on the website http://wwwabi.snv.jussieu.fr/ public/abgd/ (Puillandre et al., 2012; last access 26/02/2015) with the following parameters: Pmin 0.001; Pmax 0.1; Steps 10; $\mathrm{X}$ (relative gap width) $1.5 ; \mathrm{Nb}$ bins (for distance distribution) 20; Simple distance.

The GMYC method (Pons et al., 2006; Fontaneto et al., 2007; Monaghan et al., 2009; Fujisawa \& Barraclough, 2013) is aimed at modelling in a probabilistic framework both the coalescence processes that occur within species at population level, as described by topology and length of the branches of a phylogenetic gene tree, and the speciation processes occurring at a certain level of divergence and identified as a threshold above which all nodes describe speciation events as defined by the Yule speciation model (Yule, 1925). This approach thus combines standard coalescent models that consider the diversification within populations (Hudson, 1991; Wakeley, 2008) with those models that describe the branching pattern of speciation events (Nee, 1994, 2001; Nee et al., 1994). The method evaluates, by means of a likelihood test, alternative scenarios by assessing several thresholds as a boundary between intra- and inter-specific dynamics, and fitting the best one for delimiting the species encompassed by the gene tree under analysis. The analyses were performed on the cox 1 dataset by using the multiple-threshold version of the method (Monaghan et al., 2009) implemented by the R package splits (Ezard et al., 2009) version 1.0-18 with the following parameters: method $=$ 'multiple', interval $=\mathrm{c}(0,10)$.

\section{Morphological analysis}

In order to test the taxonomic pattern revealed by the molecular analyses, we performed a morphological analysis of the specimens used in molecular work. We also studied the T. mortadelo holotype, although we were not permitted to extract DNA from it for analysis. Morphological data collected by one of us (Enzo Colonnelli) over many years of observations from hundreds of specimens preserved in museums and private collections worldwide were also used. We found that the only available key (Alonso-Zarazaga \& Sánchez-Ruiz, 2002) to these Trichosirocalus species was unreliable to identify the three purported species of the T. horridus complex. In the following section we list the few characters that permit identification of the valid species. The morphological characters of specimens were primarily studied using a Wild M5 microscope with up to $50 \times$ magnification. Among the measures reported by Alonso-Zarazaga \& Sánchez-Ruiz (2002), we selected and reported here only the total body length, as all other ratios quoted in the above paper, and verified by us upon studied specimens, were variable to such an extent as to be generally useless to discriminate the species of this complex. Only the body length measures were diagnostic for species discrimination. Photographs of the holotype of T. mortadelo were taken with a Nikon D90 camera fitted with 
an AF Micro Nikkor $60 \mathrm{~mm}$ lens and then enhanced using the programmes Helicon Focus and Adobe Photoshop PS4.

\section{Results and discussion \\ Molecular genetic analyses}

We obtained a fragment of nearly 650 bp from 168 individuals collected in the field for the cox 1 marker and a fragment of nearly $880 \mathrm{bp}$ from 134 specimens for the ef $1 \alpha$ nuclear marker. Only the cox 1 marker was successfully amplified from the outgroup taxon, $T$. troglodytes. The alignment was cut at the shortest aligned sequence, giving a final set of sequences each $621 \mathrm{bp}$ long for cox 1 and $760 \mathrm{bp}$ for ef $1 \alpha$. The two collapsed alignments consisted of 45 and 10 unique haplotypes, respectively, for $\operatorname{cox} 1$ and ef1 $\alpha$, and Tables S2 and S3 (see supplementary material) list the distribution of the scored haplotypes for the two markers among all sequenced specimens and the accession numbers of the nucleotide sequences deposited in the NCBI/EMBL/DDBJ databanks.

The topologies obtained by NJ, that performed on the data of the $p$ uncorrected distance pairwise matrix, are illustrated in fig. 2a, b. Both trees ( $\operatorname{cox} 1$ and $e f 1 \alpha)$ show two clear clusters in the analysed ingroup ( $T$. horridus species complex) with good bootstrap support (100 on $\operatorname{cox} 1$ tree; 79 on ef1 $\alpha$ ). In fig. $2 \mathrm{a}$, b, the $p$ uncorrected distance values among the scored groups are listed. The $p$ values between the two clusters, representing T. horridus and T. briesei, are 0.109 and 0.016 for cox 1 and ef1 $\alpha$, respectively. The $T$. horridus cluster is somewhat variable (average within- $p$ distance $=0.015$ and 0.003 for $\operatorname{cox} 1$ and $e f 1 \alpha$, respectively), showing a structure grossly related to the sampled geographical areas (i.e., Spain, France, Germany [including Canada, Australia and New Zealand], Italy [including the USA], Turkey and Georgia). On the other hand, the $T$. briesei cluster is relatively homogeneous, with low $p$ values (average within distance $=0.002$ and 0.000 for $\operatorname{cox} 1$ and ef1 $\alpha$, respectively), also mirroring the smaller extent of the geographical distribution of the sampled individuals.

Maximum clade credibility trees from the Bayesian analyses are depicted in figs 3 and 4; again both trees display two clusters in the ingroup, with high support values (e.g., posterior probability 1.0 for both T. horridus and T. briesei cox1). As for the NJ trees, one of the two clusters encompasses a larger amount of genetic variation, probably due to a wider geographical distribution of the sampled individuals. The NJ and Bayesian topologies obtained from the analysis of all haplotypes of both markers do not differ substantially (figs 2a, b, 3 and 4), strengthening our results. The trees show quite clearly that there are two taxa in our ingroup (i.e., T. horridus and T. briesei), both with high support values (100 as bootstrap value for NJ trees and 1.0 as posterior probability in the Bayesian trees). This is also confirmed by the $p$ distance values on the $\mathrm{NJ}$ tree (fig. 2a, b) and the results of the ABGD analysis (fig. 5; see below). The cluster labelled as T. horridus includes adult specimens (see Table S2 and S3 for details) collected feeding on Carduus or Cirsium and identified on morphological characters as $T$. horridus. It also includes a few larvae assigned to T. horridus on their genetic characters. The T. briesei cluster includes all the specimens morphologically identified as T. briesei that were collected feeding on Onopordum spp. in Spain and Australia. It is noteworthy that the specimens collected in New Zealand as larvae on the three most important host plants (C. nutans, Cirsium vulgare (Savi) Ten. and $O$. acanthium) were all included in the $T$. horridus cluster.
This is contrary to the assertion by Alonso-Zarazaga \& Sánchez-Ruiz (2002) that each of these host plants should have only one associated weevil species, T. mortadelo, T. horridus and T. briesei, respectively. This supports the previously reported conclusion of a survey carried out by Groenteman et al. (2008) that currently only T. horridus occurs in New Zealand.

Results from the ABGD approach are depicted in fig. 5 and table 1. Figure 5a illustrates the distribution of the pairwise distances for the whole dataset, showing two modes that reflect intraspecific (low values) and interspecific (high values) distances, with a marked gap between them. The gap is mirrored in the steep slope in fig. 5b, in which the ranked pairwise distances are plotted. Table 1 lists the partitions found during the ten recursive steps in the ABGD analysis, lumping the cox1 sequences in groups as first-species-partition hypotheses (Puillandre et al., 2012). Partitions 1-5 $\quad(P=0.001000-$ 0.007743 ) were excluded for the oversplitting of the sequences in a high number of first-species-partition hypotheses and the consequent incongruence with the results of the phylogenetic analyses and the ecological and morphological evidence. The incongruence was always located in the sequences assigned to T. horridus in other statistical analyses. Partitions 6-10 $(P=0.012915-0.100000)$ perfectly match the phylogenetic, GMYC, morphological and ecological evidence. Overall the ABGD results clearly suggest the existence of a marked barcoding gap, further strengthening the hypothesis that there are only two species in the T. horridus species complex.

The analyses of the relationships among the haplotypes, as depicted in the Bayesian tree of fig. 3, by using the GMYC method with multiple thresholds, resulted in an oversplitting of our dataset into more than ten putative species (fig. 6; see the figure legend for more explanation) that clearly do not correspond to evolutionary units at specific rank. Many authors have recently discussed the oversplitting behaviour of the GMYC model when sequences, or haplotypes, span a large geographical extent, suggesting poor performance of the model when isolation by distance is manifest (Bergsten et al., 2012; Talavera et al., 2013). Our group \# 1 encompasses T. horridus, which we sampled from the Iberian Peninsula to Georgia. This sampling scheme captured the natural genetic variation among geographically separated populations of this taxon. We then decided to limit the influence of the divergence likely due to isolation by distance, by analysing a subset of our dataset, only including the haplotypes scored for the specimens that were sampled within the Iberian Peninsula (that includes the ingroup and the outgroup). We ran the Beast analyses with the Iberian subset of haplotypes and then applied the GMYC model. The new results, shown in fig. 7, clearly suggest, once more, to split the ingroup (T. horridus species complex) into two distinct evolutionary lineages, that is two species, which we refer to as T. horridus and T. briesei.

\section{Morphological analysis}

Morphological characters of some 1550 adults were studied during a span of about 35 years, starting in the mid-1970s, when one of us (Enzo Colonnelli) was asked by the European Biological Control of Weeds Laboratory (EBCL) of the United States Department of Agriculture to identify specimens of Trichosirocalus reared chiefly from C. nutans and C. macrocephalus Desf. prior to the importation of adults weevils from Italy into the USA for biological control Musk Thistle 
A. De Biase et al.

(a)

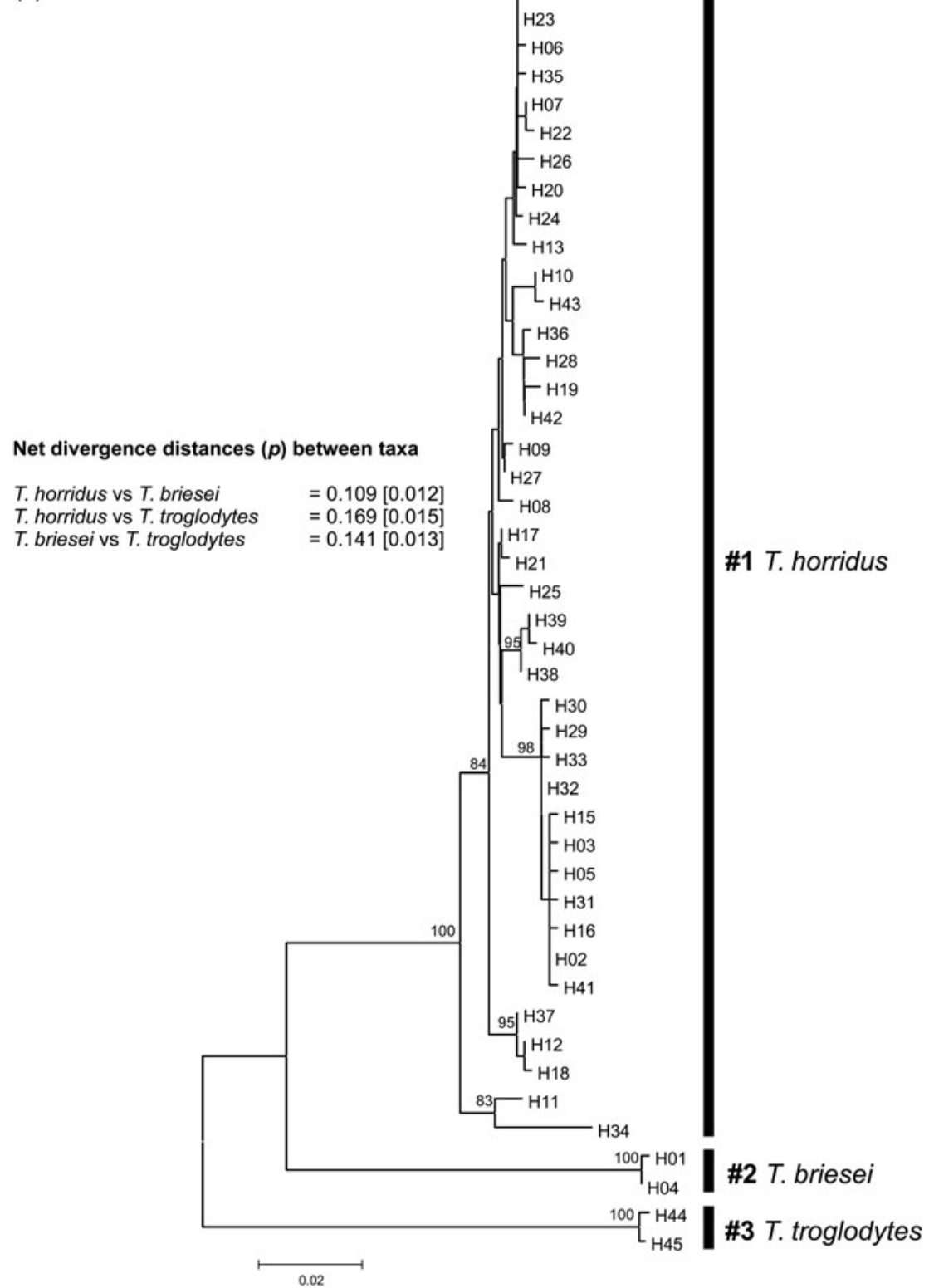

(b)

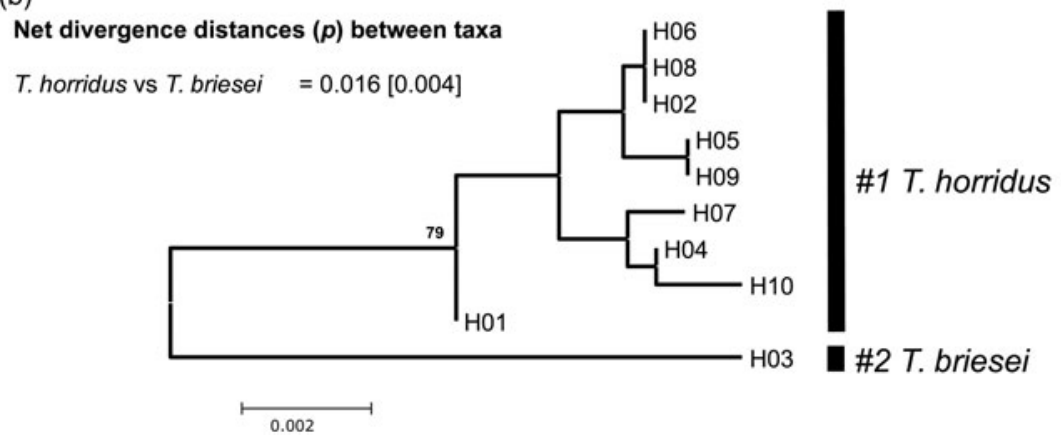

Fig. 2. NJ trees for (a) cox1 and (b) ef1a genes. Net divergence distances ( $p$ ) between T. briesei, T. horridus and T. troglodytes. Numbers at nodes are bootstrap values. Tip labels refer to haplotypes scored and listed in Table S2 for cox1 and Table S3 for ef1a. 


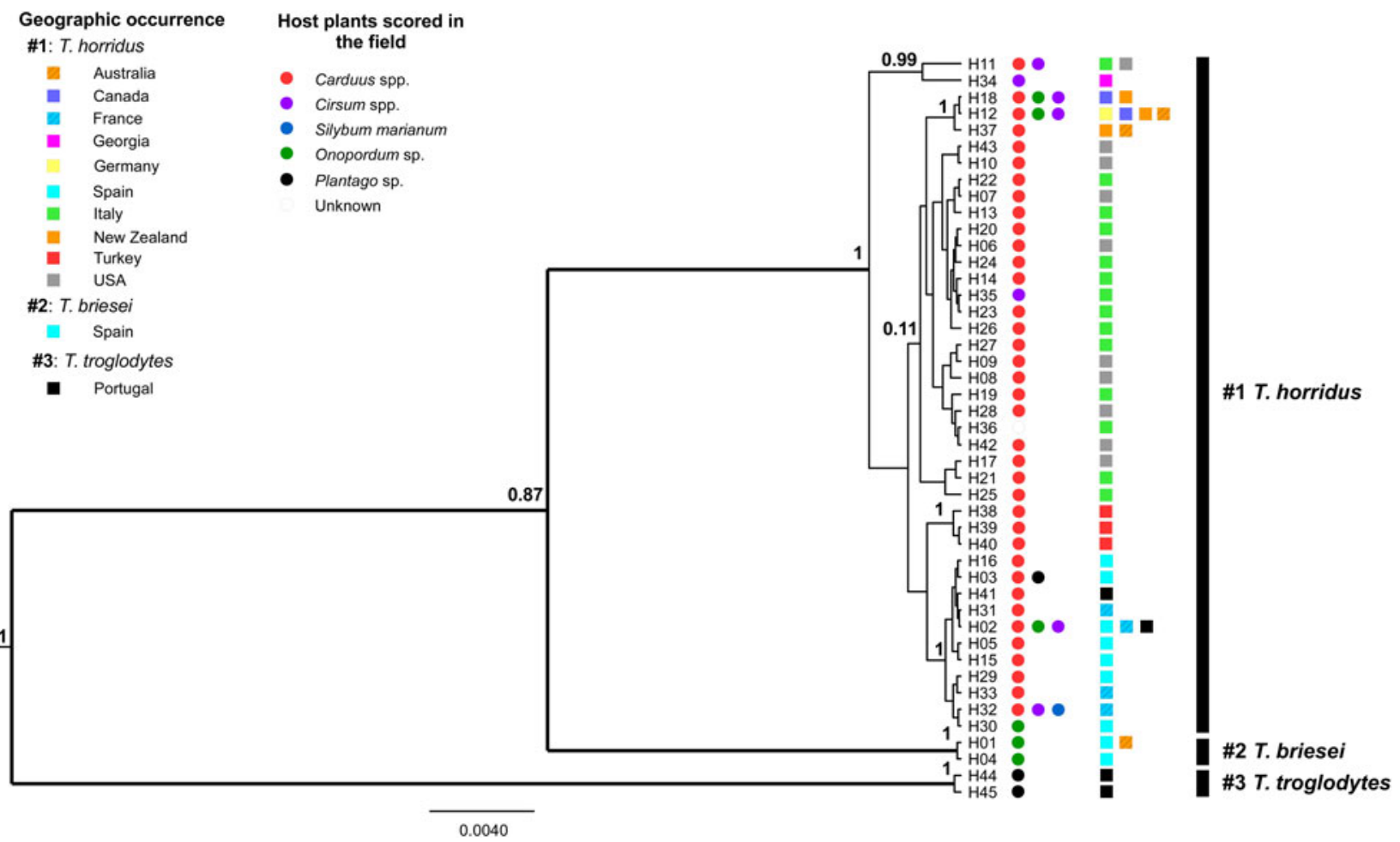

Fig. 3. Bayesian consensus tree (50\% Majority Rule) for the scored haplotypes of the cox 1 gene; figures at nodes are posterior probabilities values; T. troglodytes was used as outgroup in statistical analyses; coloured squares refer to geographical distribution of haplotypes and coloured spots to the host plants on which adults were collected in the field (suggesting at least trophic association between the insect and the plant; no evaluation was made regarding the oviposition behaviour).

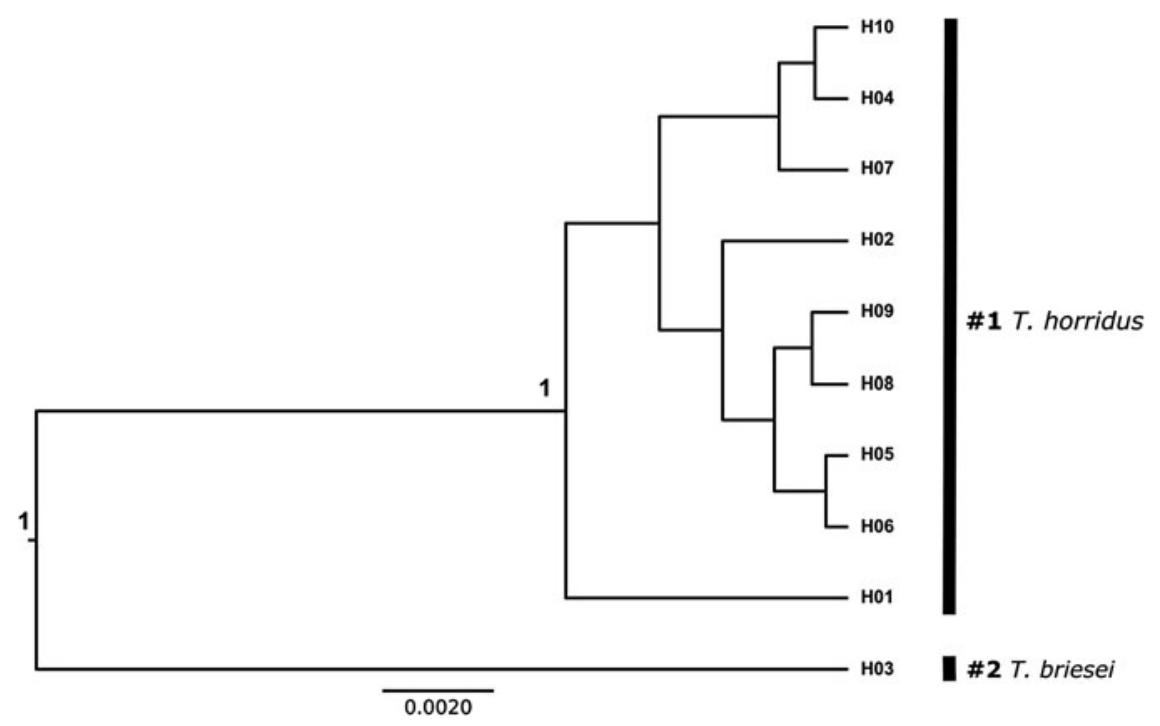

Fig. 4. Consensus tree (50\% Majority Rule) obtained by Bayesian analysis of ef1a haplotypes; figures at nodes are posterior probabilities values.

(Kok, 2001). EBCL scientists provided also precise collecting and biological data for Trichosirocalus (Boldt \& Campobasso, 1978, 1981; Boldt et al., 1980), until then poorly known apart from scattered records of adults or larvae and the plants on which they were found (Perris, 1877; Kleine, 1910; Wagner, 1944; Hoffmann, 1955; Scherf, 1964; Dieckmann, 1972). The life history and host plants of the T. horridus complex were extensively studied before and after the release in the USA, 
(a)

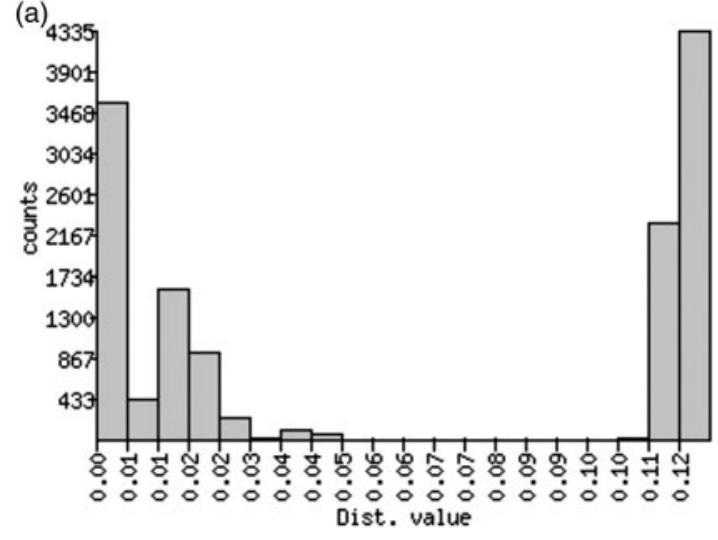

(b)

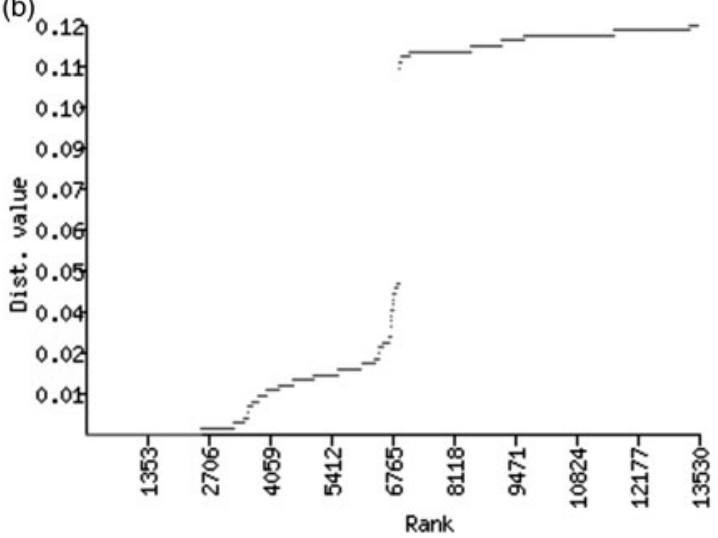

Fig. 5. Automatic Barcoding Gap Discovery (ABGD) web results using simple distance measure of distance for cox1; (a) distribution of pairwise distances among all sampled individuals shows two modes (low and high distance values) related to intraspecific and interspecific distances, respectively; (b) the same values plotted in ranked order showing a steep slope at the barcoding gap value.

Table 1. Results of the ABGD method ( $P$ value representing prior maximum divergence of intraspecific diversity; in our analysis it ranging between 0.001 and 0.1 ).

\begin{tabular}{lll}
\hline Partition id & $\begin{array}{l}\text { Groups } \\
\text { within } \\
\text { partition }\end{array}$ & $\begin{array}{l}\text { Prior } \\
\text { maximal } \\
\text { distance } P\end{array}$ \\
\hline 1 & 22 & 0.001000 \\
2 & 9 & 0.001668 \\
3 & 9 & 0.002783 \\
4 & 9 & 0.004642 \\
5 & 9 & 0.007743 \\
6 & 2 & 0.012915 \\
7 & 2 & 0.021544 \\
8 & 2 & 0.035938 \\
9 & 2 & 0.059948 \\
10 & 2 & 0.100000 \\
\hline
\end{tabular}

Canada, Australia and New Zealand (Ward et al., 1974; Kok, 1975; Trumble \& Kok, 1979; Boldt et al., 1980; Boldt \& Campobasso, 1981; Rizza \& Spencer, 1981; Jessep, 1989; Kok \& Mays, 1989; Briese et al., 1994, 2002c; Woodburn, 1997). However, after the description of T. briesei and T. mortadelo by Alonso-Zarazaga \& Sánchez-Ruiz (2002) there were very few records of either of these species, apart from the inclusion of their names in a world catalogue (Colonnelli, 2004) and in a Palaearctic catalogue (Colonnelli, 2013) of Ceutorhynchinae, and the mention by Groenteman et al. (2008) of their possible presence in New Zealand. Trichosirocalus briesei was added by Pelletier (2012) to the fauna of Morocco based on the study by Alonso-Zarazaga \& Sánchez-Ruiz (2002) and recorded from some additional Spanish localities reported by AlonsoZarazaga et al. (2006) and Alziar \& Lemaire (2012), whereas T. mortadelo was just recorded from Germany after Alonso-Zarazaga \& Sánchez-Ruiz (2002) by Rheinheimer \& Hassler (2010), who also expressed, on page 782, some doubts about the distinctiveness of these two species. None of these reports was based on new material or a critical evaluation of the study by Alonso-Zarazaga \& Sánchez-Ruiz (2002).

Our morphological study of the T. horridus complex revealed that some characters used by Alonso-Zarazaga \& Sánchez-Ruiz (2002), including the different host plants, are either unreliable or erroneous, due to both the possibility of T. horridus developing on Cirsium, Carduus and Onopordum (Hoffmann, 1955; Scherf, 1964; Dieckmann, 1972; Groenteman et al., 2008) and the morphological variability of this species across its wide geographical range (EC, personal observation). In addition, due to morphological variability, the shape of spermatheca is not diagnostic, and the softness of the ovipositor subjects it to easy deformation. Our examination of the aedeagi of numerous specimens indicates that the differences between T. horridus and T. mortadelo, as stated by Alonso-Zarazaga \& Sánchez-Ruiz (2002), are due to their depiction from slightly different angles of view. Unfortunately the aedeagus of the holotype of T. mortadelo is embedded in Dimethyl hydantoin formaldehyd (DMHF) and we did not have permission to dissolve this mounting medium in order to better examine the aedeagus. However, in apical view the apex of the penis is sinuous like those of all other T. horridus males we studied (fig. 8e). In addition, the temones (the pair of basal apodemes of the penis) are not really as short as depicted in their figures (fig. 8c, d). We thus conclude that the shape of the penis of the T. mortadelo holotype falls within the variation of $T$. horridus (fig. 8e, f) as described in Alonso-Zarazaga \& Sánchez-Ruiz (2002) and that genital differences illustrated by these authors appear to be due to improper mounting, which changes the angle of view of the curved penis (fig. 8c, e). Also, the appearance of the internal sac of T. mortadelo, as sketched in fig. 17 of Alonso-Zarazaga \& Sánchez-Ruiz (2002), depends on how the triangular spiculum is placed inside the soft internal sac of the studied individual. Therefore this character is also unreliable.

In conclusion, our morphological and genetic analyses support the recently established synonymy by Pullen et al. (2014) of T. mortadelo Alonso-Zarazaga \& Sánchez-Ruiz (2002) with T. horridus (Panzer, 1801). Our results also confirm the contention that only one species (T. horridus) was introduced to $\mathrm{New}$ Zealand (Groenteman et al., 2008; Cullen \& Sheppard, 2012; Sagliocco et al., 2012). We conclude that the T. horridus complex includes only two species, T. horridus (Panzer, 1801) and T. briesei Alonso-Zarazaga \& Sánchez-Ruiz (2002).

Ecological data from the literature also do not support the existence of more than two different species in the T. horridus complex. In fact, Ward et al. (1974) reported the possibility of 


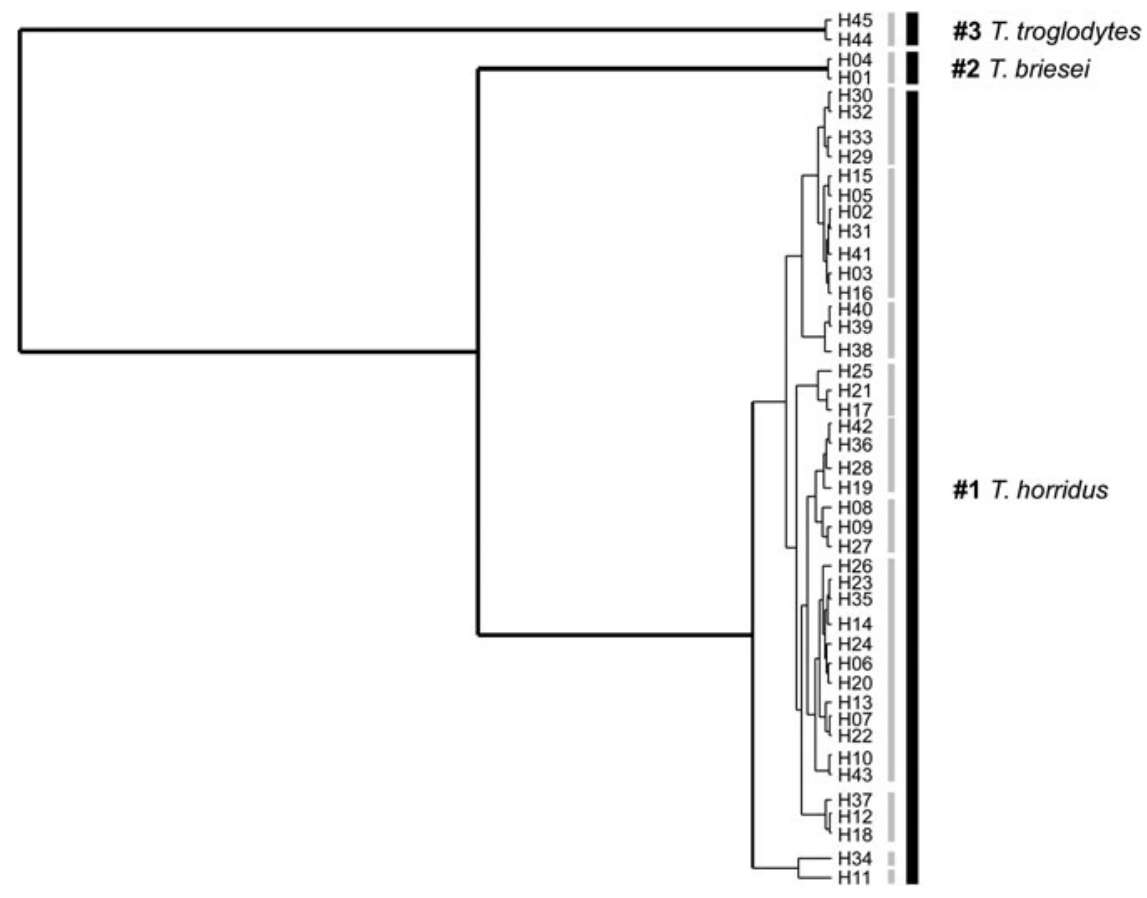

Fig. 6. General Mixed Yule Coalescent (GMYC) results obtained by analysing the tree in fig. 3 that depicts the phylogenetic relationships among all haplotypes found within our cox1 dataset. Each light grey vertical bar groups haplotypes referring to putative species according to GMYC model. Likelihood values are: $L_{0}=395.4515$ for the null model; $L_{\mathrm{GMYC}}$ ultiple $=403.1648$ for the GMYC model; Likelihood Ratio Test $P=0.00045^{* * *}$; number of ML clusters 10 (confidence interval 3-12); number of ML entities 12 (confidence interval 3-15). The black vertical bars with species names emphasize the oversplitting likely due to the genetic variation within the T. horridus dataset.

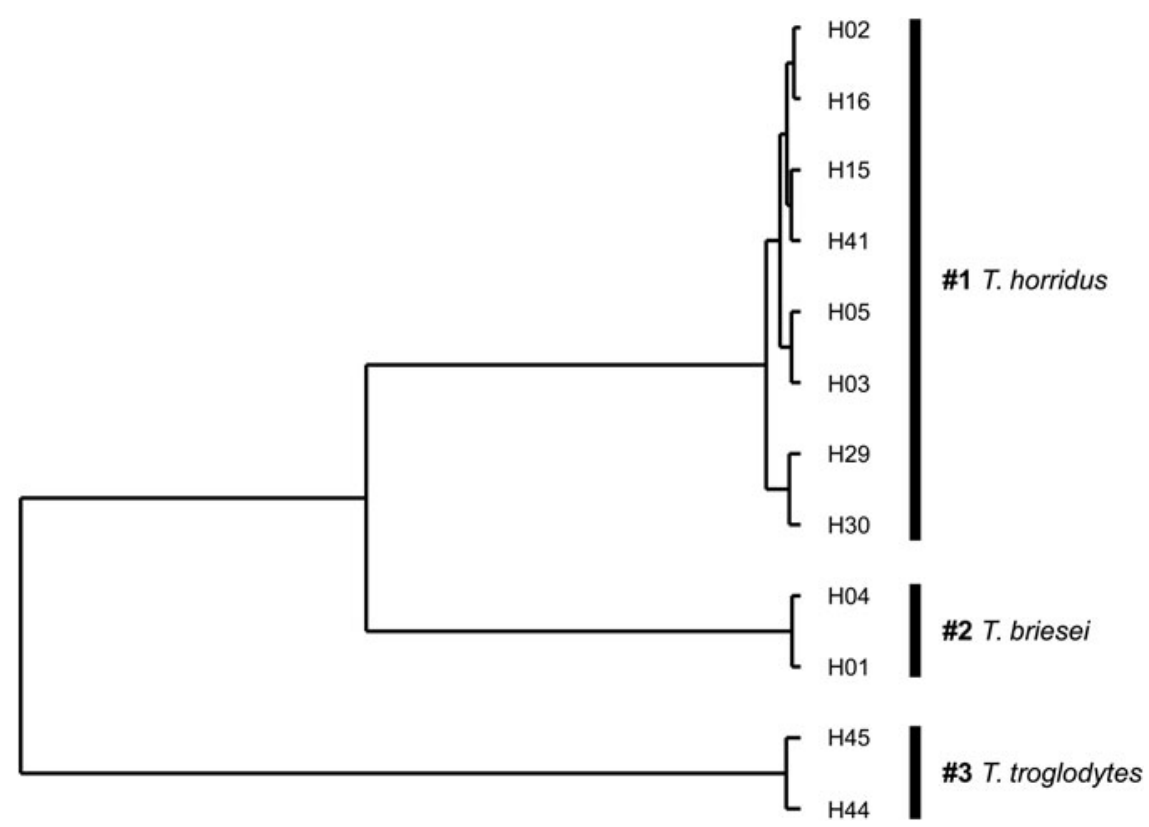

Fig. 7. General Mixed Yule Coalescent (GMYC) results obtained by analysing phylogenetic relationships among haplotypes scored only from the Iberian Peninsula, where T. horridus and T. briesei both occur. Black bars refer to putative species according to GMYC model. Likelihood values were: $L_{0}=79.44406$ for the null model; $L_{\mathrm{GMYC}}$ ultiple $=84.23986$ for the GMYC model; Likelihood Ratio Test $P=0.00826^{* *}$. 


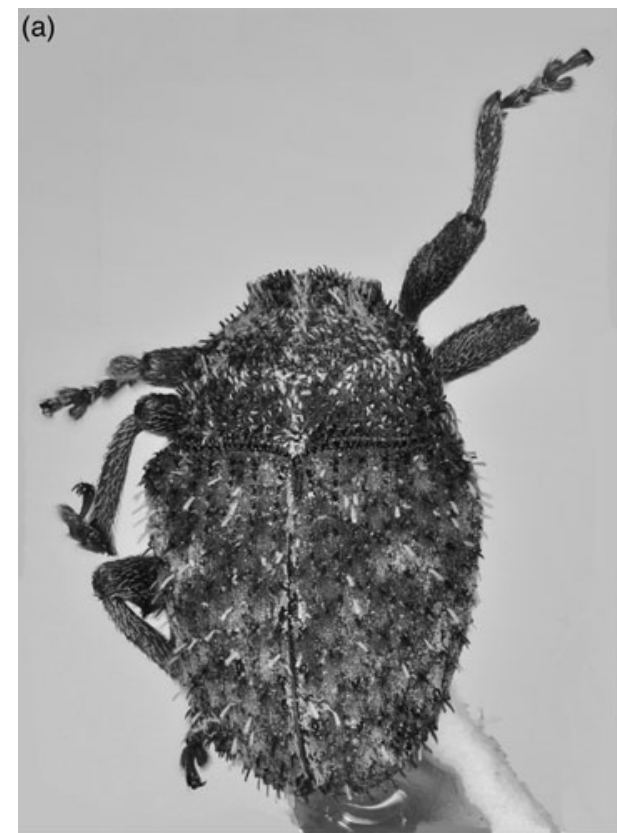

(c)

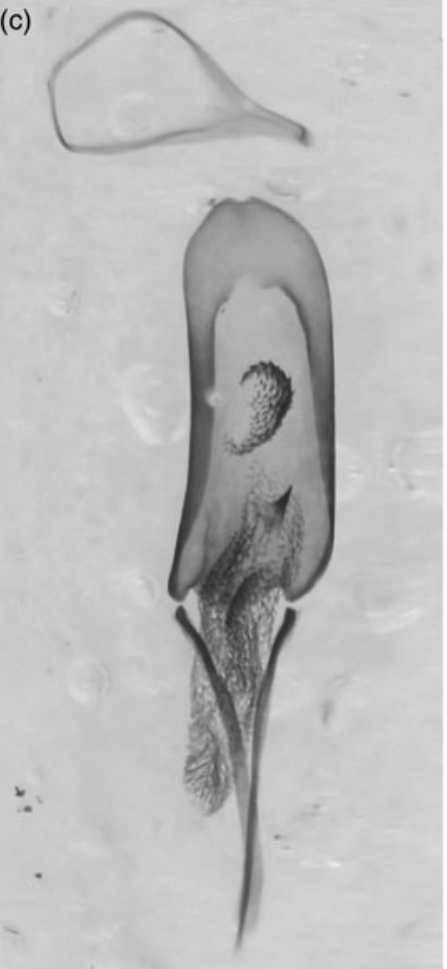

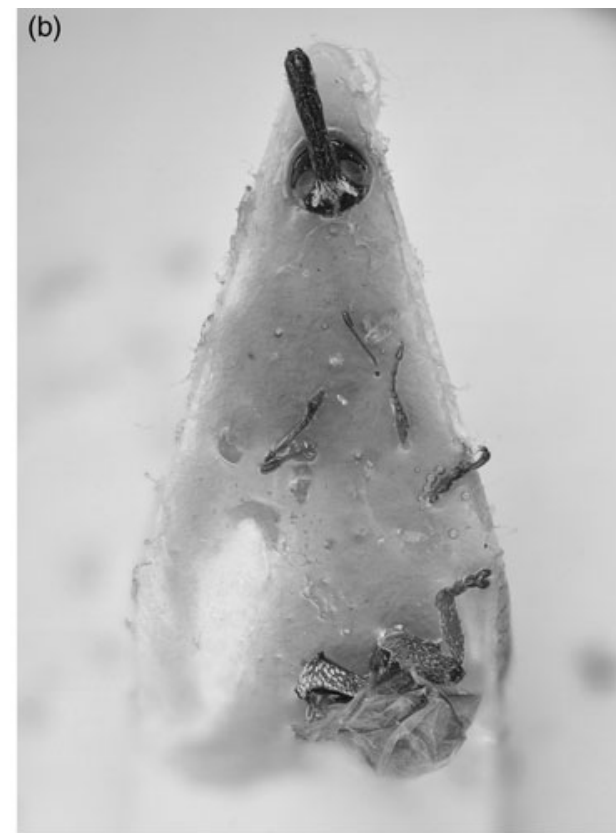

(e)

(f)
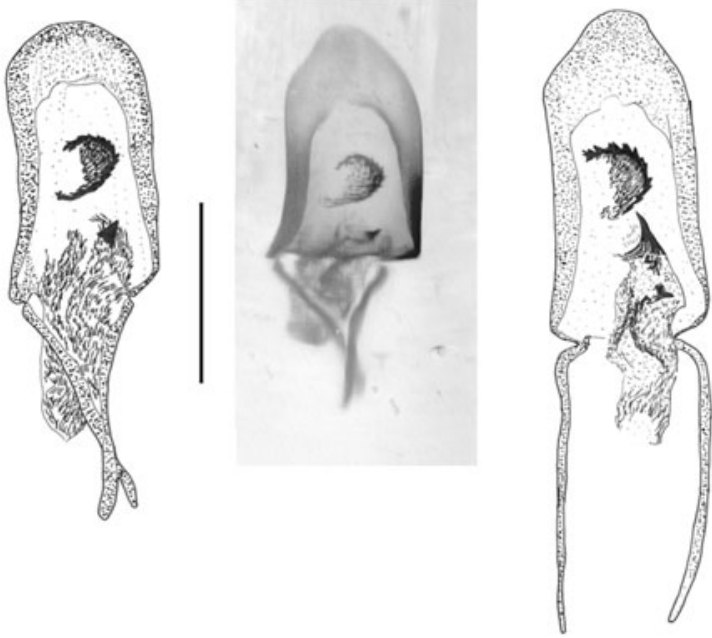

Fig. 8. Photos of holotype of Trichosirocalus mortadelo Alonso-Zarazaga \& Sánchez-Ruiz (a and b). Aedeagus embedded in DMHF in dorsal (c) and dorsoapical (e) view. Drawing of penis in dorsal view (d) by Alonso-Zarazaga \& Sánchez-Ruiz (2002). Drawing of penis in dorsal view (f) of T. horridus (Panzer) by Alonso-Zarazaga \& Sánchez-Ruiz (2002).

neonate Italian T. horridus developing up to the third instar on Carduus and Cirsium, but not on Cynara, in larval transfer experiments. This scenario was described in previous experiments carried out by Zwölfer (1965). Boldt et al. (1980) dissected plants growing in the field in Italy and found most larvae in C. nutans, with small numbers in C. pycnocephalus and Galactites tomentosa, but none in Onopordum, Silybum, Carthamus, Cynara or Sonchus. May (1993) described the larva of T. horridus completing its development on Carduus in New Zealand. Woodburn \& Swirepik (2002) were able to 

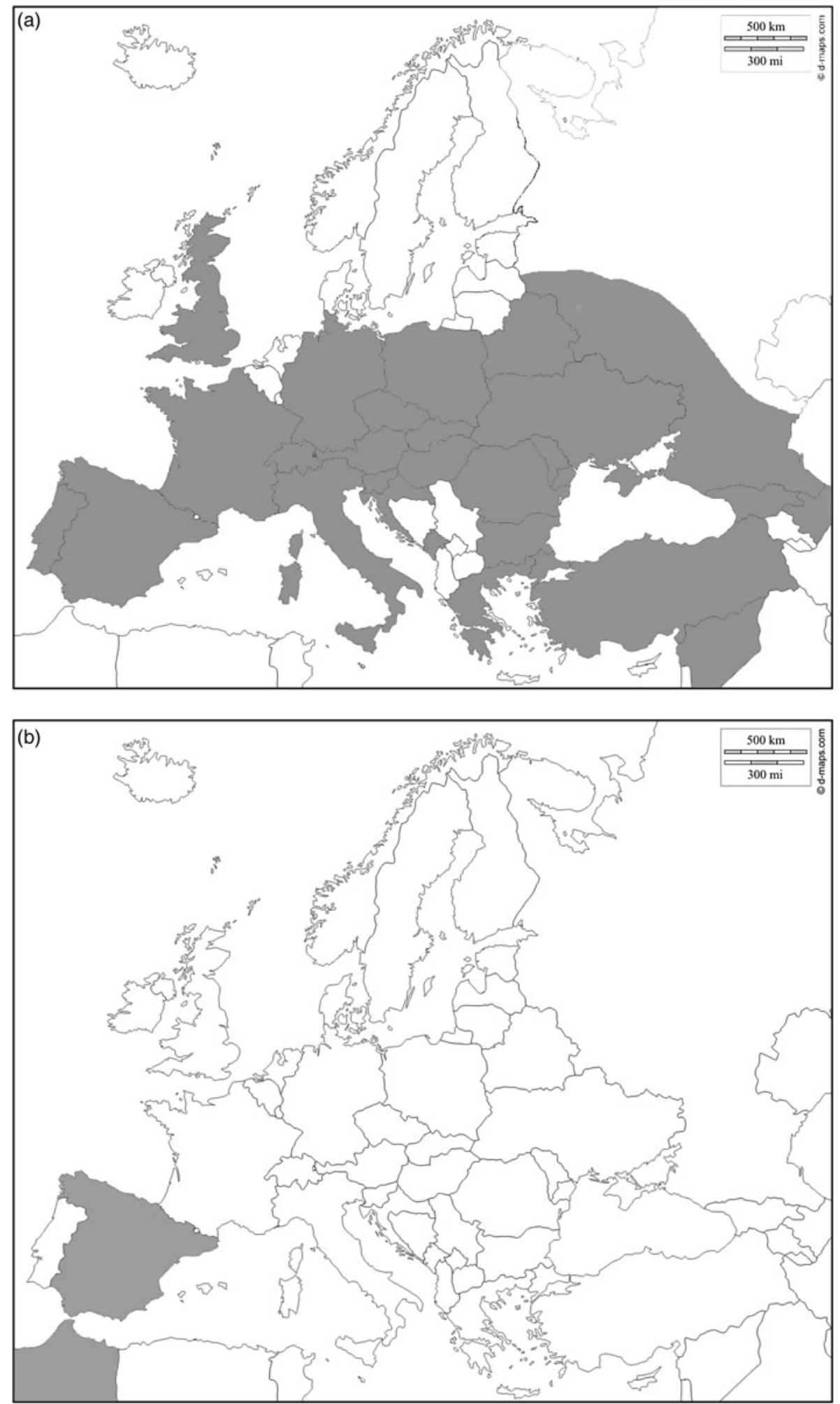

Fig. 9. Estimated native distribution of T. horridus (a) and T. briesei (b). 
establish T. horridus on Cirsium vulgare in Western Australia but concluded this host to be less suitable than $C$. nutans. Groenteman et al. (2008) reported T. horridus from C. nutans, C. vulgare and O. acanthium in New Zealand, and the results of our genetic analyses confirm that all the specimens received from these three plants in that country are T. horridus. In the USA, Trichosirocalus weevils were released to control Carduus spp. but have been reported to attack also Cirsium discolor (Muhl. ex Willd.) Spreng. in Virginia (McAvoy et al., 1987), Cirsium altissimum L. Hill in Nebraska (Takahashi et al., 2009) and C. altissimum, C. carolinianum (Walt.) Fern \& Schub., C. discolor, C. horridulum Michx. and C. muticum Michx. in Tennessee (Wiggins et al., 2009). All specimens that we have morphologically and genetically analysed from the USA are T. horridus.

Finally, during our fieldwork adult specimens of T. horridus were collected on Carduus spp. and Cirsium spp. in complete syntopy (e.g., Perpignan, France [personal records]; Otago, New Zealand [Groentman, personal communications]), whereas T. briesei was only collected on Onopordum spp., often growing together in the same location with the other thistle species.

We agree with Alonso-Zarazaga \& Sánchez-Ruiz (2002) that T. horridus is on average smaller (total body length 3.20$4.16 \mathrm{~mm}$, almost all specimens less than $3.90 \mathrm{~mm}$ ) than T. briesei (total body length 3.96-4.64 mm). Reliable morphological features that can be used to identify female specimens of $T$. briesei are the size, usually well above $4.10 \mathrm{~mm}$ (whereas we found only a few specimens of $T$. horridus larger than $4 \mathrm{~mm}$ ), together with the longer second desmomere (funicular joint), at least five times longer than wide. Males of T. briesei are quite easy to identify using the external characters given by Alonso-Zarazaga \& Sánchez-Ruiz (2002) in their key (see also their figures): protibial mucro not concealed by apical setae; sternite 2 tumid at middle and much more convex than on sides, hind margin prominent at middle over third sternite. However, the length of the second desmomere is quite variable in T. horridus, although all T. horridus specimens studied by us have this segment more or less distinctly shorter than it is in T. briesei.

Regarding the geographical distribution of T. horridus and $T$. briesei, current data support the presence of $T$. briesei only in Spain, from where we studied several adults, and Morocco (Alonso-Zarazaga \& Sánchez-Ruiz, 2002). The single female from Austria cited by Alonso-Zarazaga \& Sánchez-Ruiz (2002) was not seen by us but is probably a large individual of $T$. horridus. Of the latter species we studied material from Austria, Canada, France, Dagestan, Georgia, Germany, Italy, New Zealand, Portugal, Spain, Turkey and USA, and reliable literature records exist from Armenia, Azerbaijan, Belarus, Belgium, Bulgaria, Croatia, Czech Republic, Great Britain, Hungary, Moldavia, Montenegro, Poland, Romania, southern European Russia, Slovakia, Slovenia, Switzerland, Syria and Ukraine (Colonnelli, 2004, 2013). The distribution of T. horridus is shown in fig. 9a, that of T. briesei in fig. $9 \mathrm{~b}$.

\section{Conclusions}

Our results indicate that $T$. horridus is a widespread, genetically and morphologically variable species that is associated with several thistle species in the tribe Cardueae (Carduus spp., Cirsium spp. and Onopordum spp.) and that occurs from Spain to the Caucasus, whereas T. briesei is restricted to Onopordum and naturally occurs only in Spain and Morocco.
We found no evidence of the existence of a third species that would correspond to T. mortadelo, and we confirm that this name is a synonym of that of $T$. horridus, as established by Pullen et al. (2014). The key of Alonzo-Zarazaga \& Sánchez-Ruiz (2002) is suitable for distinguishing T. horridus and T. briesei. To date, specimens from North America and New Zealand correspond to only T. horridus, whereas both $T$. horridus and T. briesei are established in Australia. Given the diverse genetic structure of $T$. horridus (compared with the more restricted geographical distribution and genetically less differentiated T. briesei), it could be interesting to explore its population structure across the geographical distribution area in more depth, for biological control purposes. Finally, it would be interesting to investigate the possible evolution of host shifting in New Zealand populations of T. horridus associated with Onopordum.

\section{Supplementary Material}

The supplementary material for this article can be found at http://www.journals.cambridge.org/BER

\section{Acknowledgements}

We are grateful to all colleagues and friends who assisted our study in some way; many of them by collecting specimens and others in supporting our activities in various ways: Eric M. Coombs (Oregon Department of Agriculture, OR, USA), Rosemarie De Clerck-Floate (Lethbridge Research Centre, Lethbridge, AB, Canada), Marsha DeWolf (Ministry of Forests and Range, BC, Canada), Franca Di Cristina (BBCA Onlus, Rome, Italy), Andre Gassmann (CABI, Delemont, Switzerland), Richard A. Grantham (Oklahoma State University, OK, USA), Ronny Groenteman (Landcare Research, Lincoln, New Zealand), Michèle Guedj (BBCA Onlus, Rome, Italy), Francesca Lecce (ENEA Casaccia, Rome, Italy), John Lester (CSIRO, Canberra, Australia), Anna Metaponte (Rome, Italy), Alessandra Paolini (BBCA Onlus, Rome, Italy), Simona Primerano (Rome, Italy), Francisco Salgueira (Andoain, Spain), Gabriele Senia (Rome, Italy), Peter Sprick (Hannover, Germany), Thierry Thomann (CSIRO Entomology European Laboratory, Montferrier sur Lez, France), Greg Wiggins (University of Tennessee, Knoxville, TN, USA), and Iñigo Ugarte San Vicente (Agurain, Alava, Spain). We are deeply indebted to Mercedes París García and Miguel Ángel Alonso-Zarazaga of the Museo Nacional de Ciencias Naturales of Madrid (Spain) for giving us the possibility to study the holotype of Trichosirocalus mortadelo. A special thanks goes to Francesco Sacco, who provided his expertize to photograph the holotype of T. mortadelo and of all genitalia. This work was carried out with the financial support from the Agreement between Sapienza Rome University (Italy) and BBCA Onlus (Rome, Italy) 2011-2013 'Genetic characterization of populations of species of phytophagous insects for the biological control programmes'. USDA is an equal opportunity provider and employer.

\section{References}

Alonso-Zarazaga, M.A. \& Sánchez-Ruiz, M. (2002) Revision of the Trichosirocalus horridus (Panzer) species complex, with description of two new species infesting thistles (Coleoptera: 
Curculionidae, Ceutorhynchinae). Australian Journal of Entomology 41, 199-208.

Alonso-Zarazaga, M.A., Sánchez-Ruiz, M. \& Domingo-Quero, T. (2006) Lista preliminar de los Curculionidea (Coleoptera) de la Comunidad de Madrid (España). Graellsia 62 (número extraordinario), 43-52.

Alziar, G. \& Lemaire, J.-M. (2012) Les missions entomologiques du Muséum d'Histoire Naturelle de Nice (France) 2004-2010. Biocosme Mésogéen 29, 57-104.

Bergsten, J., Bilton, D.T., Fujisawa, T., Elliott, M., Monaghan, M.T., Balke, M., Hendrich, L., Geijer, J., Herrmann, J., Foster, G.N., Ribera, I., Nilsson, A., Barraclough, T.G. \& Vogler, A.P. (2012) The effect of geographical scale of sampling on DNA barcoding. Systematic Biology 61, 851-869.

Blaxter, M.L. (2004) The promise of a DNA taxonomy. Philosophical Transactions of the Royal Society of London. Series B: Biological Sciences 359, 669-679.

Boldt, P.E. \& Campobasso, G. (1978) Phytophagous insects on Carduus macrocephalus in Italy. Environmental Entomology 7, 904-909.

Boldt, P.E. \& Campobasso, G. (1981) Biology of two weevils, Ceutorrhynchus trimaculatus and Trichosirocalus horridus, on Carduus spp. in Europe. Environmental Entomology 10, 691-696.

Boldt, P.E., Campobasso, G. \& Colonnelli, E. (1980) Palearctic distribution and host plants of Ceutorhynchus trimaculatus and Trichosirocalus horridus (Coleoptera: Curculionidae). Annals of the Entomological Society of America 73, 694-698.

Briese, D.T. (2012) Onopordum acanthium L. - Scotch thistle Onopordum illyricum L. - Illyrian thistle hybrids. pp. 416-424 in Julien, M.H., McFadyen, R. \& Cullen, J. (Eds) Biological Control of Weeds in Australia. Collingwood, Victoria, CSIRO Publishing.

Briese, D.T., Sheppard, A.W., Zwölfer, H. \& Boldt, P.E. (1994) Structure of the phytophagous insect fauna of Onopordum thistles in the northern Mediterranean basin. Biological Journal of the Linnean Society 53, 231-253.

Briese, D.T., Pettit, W.J., Swirepik, A. \& Walker, A. (2002a) A strategy for the biological control of Onopordum spp. thistles in south-eastern Australia. Biocontrol Science and Technology 12, 121-136.

Briese, D.T., Thomann, T. \& Vitou, J. (2002b) Impact of the rosette crown weevil Trichosirocalus briesei on the growth and reproduction of Onopordum thistles. Journal of Applied Ecology 39, 688-698.

Briese, D.T., Walker, A., Pettit, W.J. \& Sagliocco, J.L. (2002c) Host-specificity of candidate agents for the biological control of Onopordum spp. thistles in Australia: an assessment of testing procedures. Biocontrol Science and Technology 12, 149-163.

Colonnelli, E. (2004) Catalogue of Ceutorhynchinae of the World, With a Key to Genera (Insecta: Coleoptera: Curculionidae). pp. 1-124. Barcelona, Spain, Argania editio.

Colonnelli, E. (2013) Subfamily Ceutorhynchinae Gistel, 1848. pp. 176-214 in Löbl, I. \& Smetana, A. (Eds) Catalogue of Palaeartic Coleoptera, Curculionoidea II. Leiden, Netherlands, Brill.

Cristofaro, M., De Biase, A. \& Smith, L. (2013) Field release of a prospective biological control agent of weeds, Ceratapion basicorne, to evaluate potential risk to a nontarget crop. Biological Control 64, 305-314.

Cullen, J.M. \& Sheppard, A.W. (2012) Carduus nutans L. - nodding thistle. pp. 118-130 in Julien, M.H., McFadyen, R.E.C. \& Cullen, J.M. (Eds) Biological Control of Weeds in Australia. Collingwood, Victoria, CSIRO Publishing.
Darriba, D., Taboada, G.L., Doallo, R. \& Posada, D. (2012) jModelTest 2: more models, new heuristics and parallel computing. Nature Methods 9, 772-772.

Dayrat, B. (2005) Towards integrative taxonomy. Biological Journal of the Linnean Society 85, 407-415.

De Clerck-Floate, R. \& Cárcamo, H. (2011) Biocontrol arthropods: new denizens of Canada's grassland agroecosystems. pp. 291-321 in Floate, K.D. (Ed.) Arthropods of Canadian Grasslands (Volume 2): Inhabitants of a Changing Landscape. Ottawa, Canada, Biological Survey of Canada.

DeSalle, R. (2006) Species discovery versus species identification in DNA barcoding efforts: response to Rubinoff. Conservation Biology, 20, 1545-1547.

DeSalle, R., Egan, M.G. \& Siddall, M. (2005) The unholy trinity: taxonomy, species delimitation and DNA barcoding. Philosophical Transactions of the Royal Society of London B: Biological Sciences 360, 1905-1916.

Dieckmann, L. (1972) Beiträge zur Insektenfauna der DDR: Coleoptera - Curculionidae: Ceutorhynchinae. Beiträge zur Entomologie 22, 3-128.

Drummond, A.J., Suchard, M.A., Xie, D. \& Rambaut, A. (2012) Bayesian phylogenetics with BEAUti and the BEAST 1.7. Molecular Biology and Evolution 29, 1969-1973.

Ence, D.D. \& Carstens, B.C. (2011) SpedeSTEM: a rapid and accurate method for species delimitation. Molecular Ecology Resources 11, 473-480.

Ezard, T., Fujisawa, T. \& Barraclough, T.G. (2009) SPLITS: SPecies' LImits by Threshold Statistics. R package. Version 1.0-18/r45. Available online at http://R-Forge.R-project. org/projects/splits / (accessed June 2013).

Folmer, O., Black, M., Hoeh, W., Lutz, R. \& Vrijenhoek, R. (1994) DNA primers for amplification of mitochondrial cytochrome c oxidase subunit I from diverse metazoan invertebrates. Molecular Marine Biology and Biotechnology 3, 294-299.

Fontaneto, D., Herniou, E.A., Boschetti, C., Caprioli, M., Melone, G., Ricci, C. \& Barraclough, T.G. (2007) Independently evolving species in asexual bdelloid rotifers. PLoS Biology 5 , e87.

Fujisawa, T. \& Barraclough, T.G. (2013) Delimiting species using single-locus data and the Generalized Mixed Yule Coalescent (GMYC) approach: a revised method and evaluation on simulated datasets. Systematic Biology 62, 707-724.

Fujita, M.K., Leaché, A.D., Burbrink, F.T., McGuire, J.A. \& Moritz, C. (2012) Coalescent-based species delimitation in an integrative taxonomy. Trends in Ecology and Evolution 27, 480-488.

Fumanal, B., Martin, J.-F. and Bon, M.C. (2005) High through-put characterization of insect morphocryptic entities by a noninvasive method using direct-PCR of fecal DNA. Journal of Biotechnology 119, 15-19.

Gaskin, J.F., Bon, M.C., Cock, M.J., Cristofaro, M., De Biase, A., De Clerck-Floate, R., Ellison, C.A., Hinz, H.L., Hufbauer, R. A., Julien, M.H. \& Sforza, R. (2011) Applying molecularbased approaches to classical biological control of weeds. Biological Control 58, 1-21.

Groenteman, R., Kelly, D., Fowler, S.W. \& Bourdôt, G.V. (2008) Which species of the thistle biocontrol agent Trichosirocalus are present in New Zealand?. pp. 145-149 in Julien, M.H., Sforza, R., Bon, M.C., Evans, H.C., Hatcher, P.E., Hinz, H.L. \& Rector, B.G. (Eds) Proceedings of the XIIth International Symposium on Biological Control of Weeds, La Grande Motte, France, 22-27 April 2007. UK, CAB International Wallingford.

Harris, P. (1984) Carduus nutans L., nodding thistle and C. acanthoides L., plumeless thistle (Compositae). pp. 115-126 in 
Kelleher, J.S. \& Hulme, M.A. (Eds) Biological Control Programs against Insects and Weeds in Canada, 1969-1980. Slough, UK, $\mathrm{CAB}$.

Hebert, P.D., Stoeckle, M.Y., Zemlak, T.S. \& Francis, C.M. (2004) Identification of birds through DNA barcodes. PLoS Biology 2, e312.

Hernández-Vera, G., Mitrović, M., Jović, J., Toševski, I., Caldara, R., Gassmann, A. \& Emerson, B.C. (2010) Host-associated genetic differentiation in a seed parasitic weevil Rhinusa antirrhini (Coleptera: Curculionidae) revealed by mitochondrial and nuclear sequence data. Molecular Ecology 19, 2286-2300.

Hoffmann, A. (1955) Faune de France. 59. Coléoptères curculionides (Deuxième partie). pp. 487-1207. Paris, France, Lechevalier.

Hudson, R.R. 1991. Gene genealogies and coalescent process. pp. 1-44 in Futuyma, D.J. \& Antonivics, J. (Eds) Oxford Surveys in Evolutionary Biology. Oxford, UK, Oxford University Press.

Janzen, D.H. (2004) Now is the time. Philosophical Transactions of the Royal Society B: Biological Sciences 359, 731.

Jessep, C.T. (1989) Introduction of the crown weevil (Trichosirocalus horridus) as an additional biocontrol agent against nodding thistle. Proceedings of New Zealand Weed and Pest Control Conference, vol 42, 52-54.

Kingman, J.F. (1982) The coalescent. Stochastic Processes and their Applications 13, 235-248.

Kleine, R. (1910) Die Lariiden und Rhynchophoren und ihre Nahrungspflanzen (Fortsetzung.). Entomologische Blätter 6, 231-244.

Kok, L.T. (1975) Host specificity studies on Ceuthorhynchidius horridus (Panzer) (Coleoptera: Curculionidae) for the biological control of musk and plumeless thistle. Weed Research 15, 21-25.

Kok, L.T. (1978) Biological control of Carduus thistles in northeastern USA. pp. 101-104 in Freeman, T.E. (Ed.) Proceedings of the IVth International Symposium on Biological Control of Weeds. Center for Environmental Programs, Institute of Food and Agricultural Sciences, Florida University. 30 August-2 September 1976, Gainesville, Florida.

Kok, L.T. (2001) Classical biological control of nodding and plumeless thistles. Biological Control 21, 206-213.

Kok, L.T. \& Mays, W.T. (1989) Comparison of the seasonal occurrence of Trichosirocalus horridus (Panzer) (Coleoptera: Curculionidae) in Virginia between 1981-83 and 1979. Journal of Entomological Science 24, 465-471.

Kok, L.T. \& Trumble, J.T. (1979) Establishment of Ceuthorhynchidius horridus (Coleoptera: Curculionidae), an imported thistle-feeding weevil, in Virginia. Environmental Entomology 8, 221-223.

Madeira, P.T., Tipping, P.W., Gandolfo, D.E., Center, T.D., Van, T.K. \& O'Brien, C.W. (2006) Molecular and morphological examination of Cyrtobagous spp. collected from Argentina, Paraguay, Brazil, Australia, and Florida. BioControl 51, 679-701.

May, B.M. (1993) Larvae of Curculionoidea (Insecta: Coleoptera): a Systematic Overview. Fauna of New Zealand Number 28. Lincoln, Canterbury, Manaaki Whenua Press.

McAvoy, T.J., Kok, L.T. \& Mays, W.T. (1987) Dispersal of Trichosirocalus horridus (Panzer) (Coleoptera: Curculionidae) in Southwest Virginia. Journal of Entomological Science 22, 324-329.

Monaghan, M.T., Wild, R., Elliot, M., Fujisawa, T., Balke, M., Inward, D.J., Lees, D.C., Ranaivosolo, R., Eggleton, P., Barraclough, T.G. \& Vogler, A.P. (2009) Accelerated species inventory on Madagascar using coalescent-based models of species delineation. Systematic Biology 58, 298-311.
Moritz, C. \& Cicero, C. (2004) DNA barcoding: promise and pitfalls. PLoS Biology 2, e354.

Mound, L.A., Wheeler, G.S. \& Williams, D.A. (2010) Resolving cryptic species with morphology and DNA; thrips as a potential biocontrol agent of Brazilian peppertree, with a new species and overview of Pseudophilothrips (Thysanoptera). Zootaxa 2432, 59-68.

Mullis, K.B., Faloona, F.A., Scharf, S.J., Saiki, R.K., Horn, G.T. \& Erlich, H. (1986) Specific enzymatic amplification of DNA in vitro: the polymerase chain reaction. Cold Spring Harbor Symposia on Quantitative Biology 51, 263-273.

Nee, S. (1994) Extinction rates can be estimated from molecular phylogenies. Philosophical Transactions of the Royal Society B: Biological Sciences 344, 77-82.

Nee, S. (2001) Inferring speciation rates from phylogenies. Evolution 55, 661-668.

Nee, S., May, R.M. \& Harvey, P.H. (1994) The reconstructed evolutionary process. Philosophical Transactions of the Royal Society B: Biological Sciences 344, 305-311.

Padial, J.M., Miralles, A., De la Riva, I. \& Vences, M. (2010) The integrative future of taxonomy. Frontiers in Zoology 7, 1-14.

Pelletier, J. (2012) Les Curculionidae du Maroc: addition et correction au catalogue de Kocher ( $5^{\mathrm{e}}$ note). L'Entomologiste 67, 217-225.

Perris, É. (1877) Larves des coléoptères. Annales de la Société linnéenne de Lyon 23, 1-430.

Pons, J., Barraclough, T.G., Gomez-Zurita, J., Cardoso, A., Duran, D.P., Hazell, S., Kamoun, S., Sumlin, W.D. \& Vogler, A.P. (2006) Sequence-based species delimitation for the DNA taxonomy of undescribed insects. Systematic Biology 55, 595-609.

Puillandre, N., Lambert, A., Brouillet, S. \& Achaz, G. (2012) ABGD, Automatic Barcode Gap Discovery for primary species delimitation. Molecular Ecology 21, 1864-1877.

Pullen, K.R., Jennings, D. \& Oberprieler, R.G. (2014) Annotated catalogue of Australian weevils (Coleoptera: Curculionoidea). Zootaxa 3896, 1-481.

Rambaut, A., Suchard, M. \& Drummond, A. (2013) Tracer v1.6. Available online at http://tree.bio.ed.ac.uk/software/tracer/

Rector, B.G., De Biase, A., Cristofaro, M., Primerano, S., Belvedere, S., Antonini, G. \& Sobhian, R. (2010) DNA fingerprinting to improve data collection efficiency and yield in an open-field host-specificity test of a weed biological control candidate. Invasive Plant Science and Management 3, 429439.

Rheinheimer, J. \& Hassler, M. (2010) Die Rüsselkäfer BadenWürttembergs. Heidelberg, Germany, Verlag Regionalkultur.

Rizza, A. \& Spencer, N.R. (1981) Field tests with the musk thistle insects, Trichosirocalus (Ceuthorrhynchidius) horridus and Ceutorrhynchus trimaculatus to determine their impact on artichoke. Environmental Entomology 10, 332-334.

Sagliocco, J.L., Kwong, R.M. \& Morley, T. (2012) Cirsium vulgare (Savi) Tenore-spear thistle. pp. 184-189 in Julien, M., McFadyen, R. \& Cullen, J. (Eds) Biological control of weeds in Australia. Clayton, Australia, CSIRO Publishing.

Saitou, N. \& Nei, M. (1987) The neighbor-joining method: a new method for reconstructing phylogenetic trees. Molecular Biology and Evolution 4, 406-425.

Scherf, H. (1964) Die Entwicklungsstadien der mitteleuropäischen Curculioniden (Morphologie, Bionomie, Ökologie). Abhandlungen der Senckenbergischen Naturforschenden Gesellschaft 506, 1-335.

Simon, C., Frati, F., Beckenbach, A., Crespi, B., Liu, H. \& Flook, P. (1994) Evolution, weighting, and phylogenetic utility of 
mitochondrial gene sequences and a compilation of conserved polymerase chain reaction primers. Annals of the Entomological Society of America 87, 651-701.

Staden, R., Beal, K.F. \& Bonfield, J.K. (1999) The Staden Package. 1998. pp. 115-130 in Misener, S. \& Krawetz, S.A. (Eds), Bioinformatics Methods and Protocols, Methods in Molecular Biology, Vol. 132. Totowa, NJ, The Humana Press Inc.

Stephens, M., Smith, N. \& Donnelly, P. (2001) A new statistical method for haplotype reconstruction from population data. American Journal of Human Genetics 68, 978-989.

Takahashi, M., Louda, S.M., Miller, T.E.X. \& O’Brien, C.W. (2009) Occurrence of Trichosirocalus horridus (Coleoptera: Curculionidae) on native Cirsium altissimus versus exotic C. vulgare in North American tallgrass prairie. Environmental Entomology 38, 731-740.

Talavera, G., Dincă, V. \& Vila, R. (2013) Factors affecting species delimitations with the GMYC model: insights from a butterfly survey. Methods in Ecology and Evolution 4, 1101-1110.

Tamura, K., Dudley, J., Nei, M. \& Kumar, S. (2007) MEGA4: molecular evolutionary genetics analysis (MEGA) software version 4.0. Molecular Biology and Evolution 24, 15961599.

Tautz, D., Arctander, P., Minelli, A., Thomas, R.H. \& Vogler, A. P. (2003) A plea for DNA taxonomy. Trends in Ecology and Evolution 18, 70-74.

Trumble, J.T. \& Kok, L.T. (1979) Ceuthorhynchidius horridus (Coleoptera: Curculionidae): life cycle and development on Carduus thistles in Virginia. Annals of the Entomological Society of America 72, 563-564.

Villesen, P. (2007) FaBox: an online toolbox for fasta sequences. Molecular Ecology Notes 7, 965-968.

Wagner, H. (1944) Über das Sammeln von Ceuthorrhynchinen. Koleopterologische Rundschau 30, 125-142.

Wakeley, J. (2008) Coalescent Theory: An Introduction. Greenwood Village, Colorado, Roberts \& Company Publishers.

Ward, R.H., Pienkowski, R.L. \& Kok, L.T. (1974) Host specificity of the first-instar of Ceuthorhynchidius horridus, a weevil for biological control of thistles. Journal of Economic Entomology 67, 735-737.

Wheeler, D.L., Barrett, T., Benson, D.A., Bryant, S.H., Canese, K., Chetvernin, V., Church, D.M., Dicuccio, M., Edgar, R., Federhen, S., Geer, L.Y., Kapustin, Y., Khovayko, O., Landsman, D., Lipman, D.J., Madden, T.L., Maglott, D.R., Ostell, J., Miller, V., Pruitt, K.D., Schuler, G.D., Sequeira, E., Sherry, S.T., Sirotkin, K., Souvorov, A., Starchenko, G., Tatusov, R.L., Tatusova, T.A., Wagner, L. \& Yaschenko, E. (2007) Database resources of the National Center for Biotechnology Information. Nucleic Acids Research 35, D5-D12.

Wiens, J.J. (2007) Species delimitation: new approaches for discovering diversity. Systematic Biology 56, 875-878.

Wiggins, G.J., Grant, J.F., Lambdin, P.L., Ranney, J.W. \& Wilkerson, J.B. (2009) First documentation of adult Trichosirocalus horridus on several non-target native Cirsium species in Tennessee. Biocontrol Science and Technology 19, 993-998.

Woodburn, T. \& Swirepik, A. (2002) Establishment of the crown weevil Trichosirocalus horridus on a novel host, Cirsium vulgare in Western Australia. p. 430 in Spafford Jacob, H., Dodd, J. \& Moore, J.H. (Eds) Proceedings of the 13th Australian Weeds Conference, 8-13 September 2002, Perth, Western Australia. Plant Protection Society of Western Australia.

Woodburn, T.L. (1997) Establishment in Australia of Trichosirocalus horridus a biological control agent for Carduus nutans, and preliminary assessment of its impact on plant growth and reproductive potential. Biocontrol Science and Technology 7, 645-656.

Yule, G.U. (1925) A mathematical theory of evolution, based on the conclusions of Dr JC Willis, FRS. Philosophical Transactions of the Royal Society of London. Series B, Containing Papers of a Biological Character 213, 21-87.

Zwölfer, H. (1965) Preliminary list of phytophagous insects attacking wild Cynareae (Compositae) in Europe. Technical Bulletin Commonwealth Institute of Biological Control 6, 81-154. 